\title{
Admission patterns and outcomes of paediatric patients admitted at the diarrhea unit of Muhimbili National Hospital (MNH)
}

\author{
By Sanyiwa John MD4 2007/08 \\ Penza Nuru MD4 2007/08
}

\begin{abstract}
OBJECTIVE

To determine patterns of admissions due to diarrhea and their outcomes of paediatric patients at Muhimbili National Hospital (MNH).

\section{METHODOLOGY}

A hospital-based prospective study including all children admitted to the Diarrhea Unit during the study period. Data was collected using content analysis checklists. Ethical clearance was sought from MNH and confidentiality in handling the information was observed. Data was analyzed using Epi-info 2002 statistical software.
\end{abstract}

\section{RESULTS}

A total of 50 children were admitted during the study period. Acute watery diarrhea was the commonest type of diarrhea (90\%). Most of the patients stayed in the ward for 4 to 10 days. Commonly associated diseases apart from diarrhea were found to be malaria, pneumonia and malnutrition. Over half of children succumbed to the illness.

\section{CONCLUSION}

The diarrhea mortality among children at the MNH diarrhea unit as reflected in this study was very high.

\section{INTRODUCTION}

Diarrheal diseases are a leading cause of morbidity and mortality among young children in lowincome countries ${ }^{1,2}$. Although oral rehydration has been shown to reduce early child mortality, the diarrhea-specific mortality in children less than 5 years of age in Africa has been estimated at about 10.6 per $1,000^{2}$.

Diarrhea is the fourth most common diagnosis in inpatients and outpatients and the fourth most common cause of death in admitted children.

The Diarrhea Unit provides care for children with diarrheal diseases of different types and etiologies, and other associated infections/conditions.

Diarrheal diseases remain the leading cause of mortality and morbidity among children in SubSaharan Africa, a region where unique geographic, economic, political, sociocultural, and personal factors interact to create distinctive continuing challenges to its prevention and control.

A number of different social, political, and economic factors are present in Sub-Saharan Africa which contribute to the constant morbidity from acute and persistent diarrhea, as well as intermittent epidemics of cholera and dysentery common to this region of the world. Morbidity and mortality from childhood diarrhea, whether due to invasive enteropathogens such as Shigella or the most common rotavirus, are further compounded by inappropriate household case management and the frequent misuse of antibiotics.

Given the continued importance of diarrheal disease as a major contributor to childhood morbidity and mortality in Africa, there is a clear need for vigorous efforts to implement the new Integrated Management of Childhood IIIness (IMCI) approach to improve diarrhea case management. There is also an urgent need to develop interventions to limit the spread of antimicrobial resistance among bacterial enteropathogens ${ }^{6}$.

It has generally been believed that many; if not most of the childhood deaths associated with diarrhea in developing countries are the result of acute dehydration. Undoubtedly, acute diarrhea represents a substantial proportion of the diarrheal deaths, but it may be less a predominant cause than initially believed. 
Recent information from four countries (India, Bangladesh, Brazil, and Senegal) indicates that acute watery diarrhea accounted for about $35 \%$ of all diarrhea-associated deaths ${ }^{7}$.

In Bangladesh, 40 percent of diarrhea-associated deaths among age group 1-11 months and only 9 percent among age group 1-4 years had acute watery diarrhea 8 .

The remainders of the diarrhea-associated deaths in these settings were associated with either acute or persistent dysentery or persistent non-dysenteric diarrhea.

In 30 villages in Senegal, 46 percent of the diarrheaassociated deaths in children under 5 years of age were with acute diarrhea, 47 percent with persistent diarrhea, and 8 percent with dysentery. Whereas childhood mortality rates from diarrhea were expected to decrease by 30 to $50 \%$ in most areas of the world between 1990 and 2000, the decline in Sub-Saharan Africa was estimated to be only $3 \%^{3}$.

Consequently, approximately 40\% of childhood deaths from diarrhea worldwide occurred in SubSaharan Africa by the year 2000, although only 19\% of the world's population under the age of five years lived in this region 4 .

This continuing epidemic deserves sustained programmatic and research attention as international public health moves on to confront newer issues in infectious disease and the changing burdens of disease associated with the demographic transition. In addition to the role of diarrhea as a primary cause of death, it may also contribute indirectly to high mortality through malnutrition and micronutrient deficiency, which are important underlying factors for a high proportion of child mortality in sub-Saharan Africa ${ }^{5}$.

It is important to know the pattern to which children are admitted to MNH's Diarrhea Unit and its relation to age, sex, type of diarrhea, treatment plan advocated as well as the outcome so as to assist in the proper planning, prevention and proper management of children. of admissions of patients in the Diarrhea Unit and the outcomes of those admissions. Variables studied included age, sex, source of referral, type of diarrhea, length of stay in the hospital, associated medical conditions and mortality.

\section{METHODOLOGY}

This was a prospective cross sectional survey carried out at the Diarrhea Unit of Muhimbili National Hospital $(\mathrm{MNH})$.

The sample population included all children admitted to the Diarrhea Unit and sample size was made up of all admissions in Diarrhea Unit of $\mathrm{MNH}$ from 18th February to 8th March, 2008. Data was collected using a content analytic checklist which was designed to cover all necessary information required in the study.

Data was collected by going through the medical records and patient files from the time of admission in the Diarrhea Unit up to the time of discharge or death. Data was screened and coded before entering into the statistical software. Data were analyzed using the Epi-info 2002 statistical software. Ethical clearance was sought from MNH and confidentiality in handling the information was observed.

\section{RESULTS}

Table 1: DISTRIBUTION OF PAEDIATRIC PATIENTS' OUTCOME

\begin{tabular}{|l|r|r|r|}
\hline \multirow{2}{*}{ Type of diarrhea } & \multicolumn{2}{|l|}{ Outcome } & Total \\
\cline { 2 - 3 } & \multicolumn{1}{|l|}{ Death } & Discharged & \\
\hline $\begin{array}{c}\text { ACUTE WATERY } \\
\text { DIARRHEA }\end{array}$ & $26(57.8 \%)$ & $19(42.3 \%)$ & 45 \\
\hline $\begin{array}{c}\text { PERSISTENT } \\
\text { DIARRHEA }\end{array}$ & $0(0 \%)$ & $2(100.0 \%)$ & 2 \\
\hline DYSENTERY & $3(100.0 \%)$ & $0(0 \%)$ & 3 \\
\hline TOTAL & $\mathbf{2 9 ( 5 8 . 0 \% )}$ & $\mathbf{2 1 ( 4 2 \% )}$ & $\mathbf{5 0}$ \\
\hline
\end{tabular}

Among the 50 patients admitted in the diarrheal unit, 45 (90.0\%) had Acute Watery Diarrhea, 29 (58.0\%) died during the study. However, $3(6.0 \%)$ of the studied patients had dysentery and they all died. 
Table 2: THE DISTRIBUTION BY SEX AND OUTCOME OF PAEDIATRIC PATIENTS

\begin{tabular}{|l|r|r|r|}
\hline \multirow{2}{*}{ SEX } & \multicolumn{2}{|c|}{ OUTCOME } & \multirow{2}{*}{ TOTAL } \\
\cline { 2 - 3 } MALE & $16(55.2 \%)$ & $14(66.7 \%)$ & $30(60.0 \%)$ \\
\hline FEMALE & $13(44.8 \%)$ & $7(33.3 \%)$ & $20(40.0 \%)$ \\
\hline TOTAL & $\mathbf{2 9}(\mathbf{1 0 0 . 0} \%)$ & $\mathbf{2 1}(\mathbf{1 0 0 . 0} \%)$ & $\mathbf{5 0}(\mathbf{1 0 0 . 0} \%)$ \\
\hline
\end{tabular}

Of the 29 patients who died in this study, 16(55.2\%) were male patients, and of the 21 patients who recovered and were discharged, 7(33.3\%) were female patients

\section{Table 3: THE FREQUENCY OF CO-MORBID CONDITIONS AMONG PAEDIATRIC PATIENTS}

\begin{tabular}{|l|r|}
\hline $\begin{array}{l}\text { Associated infections and } \\
\text { conditions }\end{array}$ & $\begin{array}{c}\text { Frequency } \\
\text { N=50 }\end{array}$ \\
\hline Pediatrics AIDS & $5(10.0 \%)$ \\
\hline Malaria & $35(70.0 \%)$ \\
\hline Meningitis & $6(12.0 \%)$ \\
\hline Pneumonia & $16(32.0 \%)$ \\
\hline Malnutrition & $12(24.0 \%)$ \\
\hline Anemia & $8(16.0 \%)$ \\
\hline Septicemia & $1(2.0 \%)$ \\
\hline Severe hypokalemia & $10(20.0 \%)$ \\
\hline
\end{tabular}

Among the 50 patients studied, Malaria 35(70.0\%) followed by Pneumonia 16(32.0\%) and malnutrition $12(24.0 \%)$, were the leading conditions associated with diarrhea among the studied patients.

Table 4: LENGTH OF STAY AND OUTCOME OF PATIENTS SUFFERING FROM DIARRHEA

\begin{tabular}{|l|c|c|c|}
\hline \multirow{2}{*}{$\begin{array}{l}\text { LENGTH OF } \\
\text { STAY }\end{array}$} & \multicolumn{2}{|c|}{$\begin{array}{l}\text { PATIENT } \\
\text { OUTCOME }\end{array}$} & \multirow{2}{*}{ TOTAL } \\
\cline { 2 - 3 } & Death & Discharged & \\
\hline $1-3$ HRS & 4 & 0 & 4 \\
\hline $4-23$ HRS & 0 & 5 & 5 \\
\hline 1 - 3 DAYS & 2 & 6 & 8 \\
\hline $4-10$ DAYS & 16 & 7 & 23 \\
\hline $11-17$ DAYS & 4 & 1 & 5 \\
\hline 18-24 DAYS & 3 & 1 & 4 \\
\hline >24 DAYS & 0 & 1 & 1 \\
\hline TOTAL & $\mathbf{2 9}$ & $\mathbf{2 1}$ & $\mathbf{5 0}$ \\
\hline
\end{tabular}

Among the 50 patients admitted, 23(46.0\%) stayed in the ward for $4-10$ days, and $16(55.2 \%)$ of them died. $1(2.0 \%)$ of the admitted patients stayed in the unit for more than 24 days. However, all four (4) patients who stayed in the unit for $1-3$ hours died.
TABLE 5: ASSOCIATION OF BREASTFEEDING AND TYPE OF DIARRHEA IN PEDIATRIC PATIENTS

\begin{tabular}{|c|c|c|c|c|}
\hline \multirow[b]{2}{*}{$\begin{array}{l}\text { FACTORS } \\
\text { ASSOCIATED } \\
\text { WITH } \\
\text { DIARRHEA }\end{array}$} & \multicolumn{3}{|c|}{ TYPE OF DIARRHEA } & \multirow[b]{2}{*}{ TOTAL } \\
\hline & \begin{tabular}{|c|} 
ACUTE \\
WATERY \\
DIAR- \\
RHEA
\end{tabular} & \begin{tabular}{|c} 
PERSISTENT \\
DIAR- \\
RHEA
\end{tabular} & DYSENTERY & \\
\hline $\begin{array}{l}\text { EXCLUSIVELY } \\
\text { BREASTFED } \\
(4-6 \text { MONTHS) }\end{array}$ & $\begin{array}{c}23 \\
(92.0 \%)\end{array}$ & $\begin{array}{c}0 \\
(0 \%)\end{array}$ & $\begin{array}{c}2 \\
(8.0 \%)\end{array}$ & 25 \\
\hline $\begin{array}{l}\text { EARLY WEANING } \\
(<4 \text { MONTHS })\end{array}$ & $\begin{array}{c}22 \\
(88.0 \%) \\
\end{array}$ & $\begin{array}{c}2 \\
(8.0 \%) \\
\end{array}$ & $\begin{array}{c}1 \\
(4.0 \%) \\
\end{array}$ & 25 \\
\hline TOTAL & $\begin{array}{c}45 \\
(90.0 \%)\end{array}$ & $\begin{array}{c}2 \\
(4.0 \%)\end{array}$ & $\begin{array}{c}3 \\
(6.0 \%)\end{array}$ & 50 \\
\hline
\end{tabular}

There was no difference in the occurrence of diarrhea among exclusively breastfed $25(50.0 \%$ ) , and early weaned $25(50.0 \%)$ pediatric patients admitted in the diarrheal unit.

\section{DISCUSSION}

This study included 50 pediatric patients, Males accounted for $60.0 \%$ of the sample most patients were aged between 7 - 12 months.

Undoubtedly acute dehydrating diarrhea represents a substantial proportion of the diarrheal deaths. In this study, of the 58\% patients who died, 89.7\% patients had Acute Watery Diarrhea and 10.3\% has Dysentery.

These finding are supported by the findings from a study ${ }^{6}$ done in four countries (India, Bangladesh, Brazil, and Senegal) which indicated that acute watery diarrhea accounted for about 35\% (25-46\%) of all diarrhea-associated deaths.

In Bangladesh7, 49\% of diarrhea-associated deaths had acute watery diarrhea. The remainders of the diarrhea-associated deaths in these settings were associated with either acute or persistent dysentery or persistent non-dysenteric diarrhea.

However, other infections and conditions which contribute to high morbidity and mortality among the diarrhea patients in this study were Malaria 70.0\%, Pneumonia 32.0\% and Malnutrition 24.0\%. These are very common in our locality unlike findings from other countries in other studies 5 where Malnutrition and Micronutrient deficiencies are more common.

Nevertheless, the breastfeeding pattern among pediatric patients in this study was not shown 
to affect the incidence of diarrheal diseases in this age group. This is in contrast to a study done in Bangladesh which showed that, exclusive breastfeeding of infants as compared to other feeding modes, was associated with significant protection against severe Enterotoxigenic Eshrerichia coli (ETEC) diarrhea. However, during the second and third years of life, the risk of this outcome was similar in both breastfed and nonbreastfed children?.

Among the 50 pediatric patients in this study admitted at the Diarrheal Unit, $46.0 \%$ stayed in the unit for 4 - 10 days, and 55.2\% of them died. 2.0\% of the admitted patients stayed in the unit for more than 24 days.

However, all four patients who stayed in the unit for less than 3 hours died as they were brought at late stages to the unit after failure of management at peripheral health facilities.

It was found that of the 50 pediatric patients recruited in this study, $58 \%$ died and $42 \%$ recovered and were discharged. Of the 58\% patients who died 89.7\%) had Acute Watery Diarrhea and 55.2\% stayed in the unit between 4 - 10 days before their death.

The mortality in the Diarrhea Unit at Muhimbili National Hospital is high as reflected in this study and this calls for much to be done to find out the possible causes of the deaths so as to allow for proper preparation of care givers as well as a timely adjustment incase of any diarrheal disease outbreaks.

\section{CONCLUSIONS AND RECOMMENDATIONS}

Diarrheal diseases remain the leading cause of mortality and morbidity of children in SubSaharan Africa, a region where unique geographic, economic, political, sociocultural, and personal factors interact to create distinctive continuing challenges to its prevention and control.

The diarrhea mortality among children at the $\mathrm{MNH}$ diarrhea unit very high, 58.0\% died despite the efforts of providing proper management to these patients through Oral Rehydration therapies and management of other conditions.

Based on the findings of this study, the following recommendations are pertinent;-

More studies should be carried out to find the possible causes of death among patients admitted in the diarrheal unit.

Need for proper preparation of care givers in managing diarrheal cases as well as a timely adjustment in case of any diarrheal disease outbreaks.

Need to encourage close monitoring of these children because they are at greater risk of developing severe dehydration and electrolyte imbalances especially hypokalaemia

Need to provide education to caretakers on hygienic practices and encourage them to seek medical assistances as soon as children get sick.

\section{ACKNOWLEDGEMENT}

We are in debt to our to our Supervisor Dr Fataki for his effort in guiding us throughout the study. We are grateful to the following, with whom we worked with in carrying out the study and preparation of this paper: Stanslaus, Annamary., Rite, Erasto., Rajabu, Latifa., Nkandala, Igembe., Pallangyo, Peter., Sam, Linda., Swai, Caroline and Ismail, Murtaza.

\section{REFERENCES}

1. Levine, M. M., G. Losonsky, D. Herrington, J. B. Kaper, C. Tacket, M. B. Rennels, and J. G. Morris. 1986. Pediatric diarrhea: the challenge of prevention. Pediatric. Infect. Dis. 5(Suppl.):29-43.

2. Snyder, S. D., and M. H. Merson. 1982. The magnitude of the global problem of acute diarrhoeal disease. A review of active surveillance data. Bull. W. H. 0. 66:605-613.

3. The Global Burden of Disease, CJC Murray \& AD Lopez. 1996

4. Department of Pediatric Gastroenterology, Umberto I Hospital, São Paulo Federal University/Escola Paulista de Medicina, São Paulo, Brazil.

5. Ulysses Fagundes-Neto. Acute Diarrhea and Malnutrition: Lethality Risk in Hospitalized Infants. Journal of the American College of Nutrition, Vol. 18, No. 4, 303-308 (1999)

6. Childhood Diarrhea in Sub-Saharan Africa - Child health research project special report

7. Fauveau et al., Programme for Control of Diarrhoeal Diseases, 1991 a Department of Pediatric Gastroenterology, Umberto I Hospital, São Paulo Federal University/Escola Paulista de Medicina, São Paulo, Brazil.

8. Clemens JD et al - International Centre for Diarrhoeal Disease Research, Dhaka, Bangladesh 